\title{
Idolatría en el Manual de ministros de indios de Jacinto de la Serna*
}

\section{Idolatry in the Manual de ministros de indios of Jacinto de la Serna}

\author{
Víctor Manuel ÁVILA ÁVILA \\ https://orcid.org/0000-0003-3012-9772 \\ Universidad Nacional Autónoma de México (México) \\ Escuela Nacional de Estudios Superiores Unidad Morelia \\ vavila@enesmorelia.unam.mx

\section{Cecilia LÓPEZ RIDAURA} \\ https://orcid.org/0000-0002-5007-4804 \\ Universidad Nacional Autónoma de México (México) \\ Escuela Nacional de Estudios Superiores Unidad Morelia \\ clopez@enesmorelia.unam.mx
}

\section{Resumen}

En este trabajo atenderemos el concepto de idolatría utilizado por el religioso secular Jacinto de la Serna en su Manual de ministros de indios para el conocimiento de sus idolatrías y extirpación de ellas, escrito en la segunda mitad del siglo XVII en la Nueva España. El concepto de idolatría mantuvo una gran fuerza en esa centuria y uno de los autores más representativos de estos temas es Jacinto de la Serna. Consideramos que la obra, a pesar de ser muy utilizada, no ha tenido un acercamiento con la profundidad que merece. Para ello se acudió a diversas fuentes, entre las que destacan documentos del Archivo General de la Nación de México, del Archivo General de Indias y del Archivo del Cabildo Catedral Metropolitano de México. También se revisaron fuentes primarias de manuscritos e impresos de la época, así como las obras de algunos de los padres de la Iglesia. Además, nos hemos valido de la revisión de historiografía para la realización de este trabajo.

Palabras clave: Indios, idolatría, evangelización, enfermedad, crimen.

\begin{abstract}
In this work we will address the concept of idolatry used by the secular religious Jacinto de la Serna in his Manual de ministros de indios para el conocimiento de sus idolatrías y extirpación de ellas, written in the second half of the seventeenth century in New Spain. The concept of idolatry regained great strength in that century and one of the most representative authors of this issue was Jacinto de la Serna. We consider that this manual, despite being widely used, has not been attend-

\footnotetext{
*Agradecemos a la DGAPA de la unAm, a través del Departamento de Fortalecimiento Académico, por la beca posdoctoral que hace posible realizar esta investigación. Damos gracias a los proyectos PAPIIT AI40418 "Hechicería indígena en el siglo xviıI en Michoacán. Edición de relatos de populares" y PAPITT IG400619 "Religiosidad nativa, idolatría e instituciones eclesiásticas en los mundos ibéricos, Época Moderna”.
} 
ed with the depth it deserves. This research is based on various sources, including documents from the Archivo General de la Nación the Archivo General de Indias, and the Archivo del Cabildo Catedral Metropolitano de México. We also reviewed some manuscripts, books from the seventeenth century and revised the historiography to carry out this work.

Keywords: Indios, idolatry, Evangelization, disease, crime.

\section{Introducción}

La historiografía latinoamericana ha retomado los estudios de las religiones nativas y las religiosidades heterodoxas en el catolicismo y ha ponderado la revisión de las persecuciones de idolatrías en la América hispana colonial. Lo que ha hecho falta en estos trabajos es poner el acento en el significado del concepto y en que éste no tenía una unidad, sino una variedad de significados, que se definen de acuerdo con el tiempo y el espacio, así como según los contextos.

La idolatría se consideró un crimen que afectaba a la sociedad, pues su mancha era en perjuicio del sistema de creencias y de parámetros considerados como correctos ética, política y jurídicamente. En el contexto hispano, y sobre todo novohispano, la idolatría fue un crimen de categoría mixta, es decir, que podría seguirse por tribunales civiles o eclesiásticos. Se entendía como un crimen civil porque era enfrentar a las autoridades, como desobediencia o rebeldía contra las reglas establecidas por la Corona española que ordenaban a sus súbditos ser católicos, además de respetar y cumplir con sus principios.

La idolatría en el arzobispado de México en la primera mitad del siglo XVII

La idolatría resultó un concepto fundamental desde la llegada de los españoles a tierras americanas. En ciertos momentos tomó mayor relevancia que en otros, pero nunca dejó de ser un tema de la agenda colonial. El siglo XVII fue importante en la reactivación de la literatura antiidolátrica porque desde finales del siglo Xvi los conflictos religiosos en Europa se reavivaron. Las leyes producidas por la monarquía española, tanto para sus territorios europeos como para los americanos, estaban encaminadas a regular y castigar la idolatría y fortalecer la religión católica, sobre todo entre los indios. 
Los católicos fueron tachados de idólatras por los movimientos protestantes, de manera particular por Martín Lutero. ${ }^{1}$ Pero esto no era nuevo, Maimónides en el siglo XII había escrito en la Guía de perplejos una categorización de las formas de idolatría en la que quedaba de manifiesto la forma en que los católicos eran una religión de idólatras por adorar imágenes y por pensar que Dios podía tener una representación física. ${ }^{2}$

Desde finales del siglo xvi el concepto de idolatría fue de gran relevancia para la teología española, ya que resultaba una manera de abarcar la gran diversidad que se integraba a la Corona de Castilla tras la guerra de Reconquista contra los musulmanes, a la par que se integraba a los habitantes del vasto continente americano a las filas de los súbditos de dicha Corona.

Durante el siglo XVII la idolatría era entendida de manera distinta de la de la centuria anterior. La idolatría al momento del encuentro estaba justificada para los misioneros e incluso para las autoridades civiles. A finales del siglo XVI se consideraba que los indios eran ya católicos convertidos, con la atenuante de ser neoconversos, pero católicos al fin de cuentas. Así, la idolatría se percibió en el siglo xviı como una práctica más perniciosa y, por lo tanto, peligrosa.

Después del Concilio Tercero Provincial Mexicano de 1585 los indios empiezan a aparecer tímidamente en juzgados civiles y eclesiásticos acusados de idolatría. Durante el siglo Xvir habrá un incremento notable de acusaciones y casos por ese crimen, sobre todo en el Provisorato, incluso ante la Inquisición, pero estos últimos en su mayoría eran desechados y sólo algunos reconducidos al foro indicado. Además, por ser un crimen del fuero mixto, también se encontrarán indios acusados de idolatría ante juzgados civiles, generalmente en corregimientos y alcaldías.

El Concilio Tercero Provincial Mexicano definió la idolatría en términos jurídicos para dar certeza en el proceder en los casos de indios idólatras. Lo que necesitaba la Iglesia hispana en ese momento era tener un aparato jurídico bien claro y que estuviera homologado con lo establecido por los decretos del Concilio de Trento. De esa manera, los concilios provinciales en los territorios hispanos respondieron para unificar las legislaciones locales con la general y también con sus particularidades, tanto

${ }^{1}$ Mina García Soormally, Idolatry and Construction of the Spanish Empire (Boulder: University Press of Colorado, 2018), 23-25.

${ }^{2}$ Maimónides, Guía de perplejos, versión de León Dujovne, prólogo de Angelina Muñiz-Huberman (México: Consejo Nacional Para la Cultura y las Artes, 2001), 138-139. 
con indios como con otros grupos recién incorporados a las filas del catolicismo, como con los musulmanes en la propia península ibérica, que fue el caso del Concilio de Granada. ${ }^{3}$

El Concilio Mexicano asoció la idolatría con la herejía, es decir, con un error en la elección entre lo correcto y lo incorrecto, como se refiere en el libro quinto, título 4o., De los herejes. De manera particular se pedía poner énfasis en los incitadores a la idolatría, que fueron llamados dogmatistas. ${ }^{4}$ Con esto se pusieron las reglas para saber cómo y de qué manera se debía proceder contra los indios que incurrieran en idolatría. Jacinto de la Serna se refirió a dicho título en su obra.

En buena parte de los textos, la idolatría era presentada como una enfermedad en el alma de los indios que parecía interferir en su juicio. No se trataba de un asunto de ignorancia, ya que se había hecho una gran campaña de enseñanza de la religión, por lo que no era el desconocimiento del cristianismo, sino una corrupción del evangelio, como lo veremos con Jacinto de la Serna. Diego Jaymes Ricardo Villavicencio señalaba que no podía haber ignorancia invencible. ${ }^{5}$

Hubo dos posiciones en relación con la idolatría: una que buscaba encontrar a los idólatras y castigarlos, y otra que pretendía la educación de los indios para que dejaran de practicar sus antiguas religiones o costumbres, aunque las hubieran adecuado a la realidad cristiana; y sólo en caso de que esto no se pudiera hacer, entonces sí recurrir a métodos coercitivos. Perú resulta un mejor ejemplo para estas dos posturas. Así, por ejemplo, el jesuita Joseph de Acosta, refiriéndose a Perú, señalaba que era necesario trabajar duro en "desarraigar de los cristianos, o de los que van a serlo, todo amor e inclinación a la idolatría”. ${ }^{6}$ Mientras que los casos de Francisco de Ávila y de Pablo Joseph de Arriaga van en el otro sentido, el de castigar con todo el rigor posible a los indios que cometían idolatría. ${ }^{7}$

${ }^{3}$ Luis Martínez Ferrer, ed., Decretos del Concilio Tercero Provincial Mexicano (1585). Edición histórico-crítica (Zamora: El Colegio de Michoacán; Roma: Universidad Pontificia de la Santa Cruz, 2009), 45-46.

${ }^{4}$ Martínez Ferrer, Decretos del Concilio, t. II, 588.

${ }^{5}$ Diego Jaymes Ricardo Villavicencio, Luz y méthodo de confesar idolatras y destierro de idolatría, segunda parte (Puebla de los Ángeles: Imprenta de Diego Fernández de León, 1692), 5.

${ }^{6}$ Joseph de Acosta, De procuranda Indorum salute, t. II (Madrid: Consejo Superior de Investigaciones Científicas, 1987), 247.

7 José Carlos de la Puente Luna, Los curacas hechiceros de Jauja. Batallas mágicas y legales en el Perú colonial (Lima: Fondo Editorial Pontificia Universidad Católica del Perú, 2007), 20. 
No se trata aquí de hacer un estudio comparativo del tratamiento de la idolatría entre la Nueva España y el Perú; sin embargo, podemos decir que estas posiciones fueron menos violentas en la Nueva España que en Perú y en general las propuestas de corregir a los indios invitaban a los religiosos a hacerlo en foros privados, como el confesionario. Sólo en algunos casos extraordinarios se encuentran castigos públicos a indios; por ejemplo, cuando los religiosos se extralimitaban en sus funciones, como sucedió con Hernando Ruiz de Alarcón al realizar actos a manera de autos de fe a los indios. ${ }^{8}$

Esta búsqueda de idólatras la debemos ver en un contexto amplio, pues responde a la variedad de guerras que enfrentó el imperio español contra los viejos enemigos que se encontraban dentro y fuera de las fronteras del imperio. Así, las campañas antiidolátricas de Perú se pueden entender en ese contexto, lo mismo que la expulsión definitiva de los musulmanes o la gran caza de brujas que tuvo lugar en Logroño. ${ }^{9}$ Por otro lado, en el contexto cristiano europeo fue también la idolatría motivo de preocupación fuera del imperio español. Un buen ejemplo de esto es la obra de Jean-Baptiste Thiers, Traité des superstitions, que se escribió en el siglo XvII pero que tuvo tal impacto que fue reimpresa en varias ocasiones. ${ }^{10}$ En dicha obra existen diversas referencias a la idolatría, por lo que debemos entender que el contexto novohispano fue sólo una de las cosas que sucedían en el contexto general de la cristiandad. La categoría de idolatría desempeñó un papel muy importante, ya que se trata de guerras contra la heterodoxia, detrás de la cual estaba el Diablo, quien intentaba quitar a Dios aliados para convertirlos en sus simpatizantes.

Para más información sobre la persecución de idolatrías, véanse Juan Carlos Estenssoro Funch, Del paganismo a la santidad. La incorporación de los indios del Perú al catolicismo, 15321750 (Lima: Institut Français d'Études Andines, Open Editions Books, 2015), 98; Nicholas Griffiths, La cruz y la serpiente. La represión y el resurgimiento religioso en el Perú colonial (Lima: Pontificia Universidad Católica del Perú, 1998).

8 "Proceso contra Hernando Ruiz de Alarcón beneficiado del pueblo de Atenango, por haber castigado unos indios en la forma que lo hace el Santo Oficio", Archivo General de la Nación (en adelante AGN), Inquisición, v. 304, exp. 39.

${ }^{9}$ Pierre Duviols, La destrucción de las religiones andinas. Conquista y colonia (México: Universidad Nacional Autónoma de México, 1977), 425. Jean Delumeau, El miedo en Occidente (siglos XIV-XVIII). Una ciudad sitiada (Barcelona: Taurus, 2019), 331-332.

${ }^{10}$ Jean-Baptiste Thiers, Traité des superstitions qui regardent les sacramens selon l'Ecriture sainte, les décrets des conciles, et les sentimens des Saints peres (París: Jean de Nully, 1704), 119. 
El Manual de ministros de indios de Jacinto de la Serna

Tenemos pocos datos de Jacinto de la Serna y tampoco es la intención de este trabajo seguir la pista biográfica; recordemos que no es una investigación sobre la persona sino sobre un concepto. ${ }^{11}$ Sin embargo, todos somos producto de una historia personal y ese camino recorrido es lo que lo llevó a escribir el Manual de ministros. Ana Silvia Valdés señala que Jacinto de la Serna nació en el año de $1597 .{ }^{12}$ Fue "Bachiller en Artes, colegial y dos veces rector del Colegio de Nuestra Señora de Santos"13 en la ciudad de México. También fungió como beneficiado ${ }^{14}$ de los partidos ${ }^{15}$ de Tenancingo y de Xalatlaco. ${ }^{16}$ Dichos beneficios los obtuvo por oposición y no por designación. Desde entonces se tomó muy en serio la búsqueda de los indios idólatras. En 1627 solicitó ser nombrado capellán de la capellanía ${ }^{17}$ de Rodrigo de Vargas. ${ }^{18}$ La Real y Pontificia Universidad de México le entregó

${ }^{11}$ Para más información de la biografía de Jacinto de la Serna, véase Ana Silvia Valdés, "Jacinto de la Serna: aspectos de su vida y obra" (tesis de licenciatura en Historia, Universidad Nacional Autónoma de México, 2006).

12 Ana Silvia Valdés Borja, “Jacinto de la Serna”, en Historiografía mexicana. Volumen II. La creación de una imagen propia. La tradición española. Tomo 2: Historiografía eclesiástica, coord. de Rosa Camelo y Patricia Escandón (México: Universidad Nacional Autónoma de México, Instituto de Investigaciones Históricas, 2012), 1435.

13 "Relación de méritos y servicios del Dr. Jacinto de la Serna", Archivo General de Indias (en adelante AGI), Indiferente, v. 194, n. 4, f. 1r. Utilizamos este documento como fuente principal de los datos biográficos de Serna, pero se pueden encontrar en otras partes, como en el mismo "Manual de ministros". Asimismo, otros autores han hecho uso de este y otros documentos. Véase David Tavárez, Las guerras invisibles. Devociones indígenas, disciplina y disidencia en el México colonial (Oaxaca: Universidad Autónoma Benito Juárez de Oaxaca; Zamora: El Colegio de Michoacán; México: Centro de Investigaciones y Estudios Superiores en Antropología Social; México: Universidad Autónoma Metropolitana Iztapalapa, 2012), 166. Este autor cita más fuentes del AGI y del AGN.

${ }^{14}$ Beneficiado: "También se suele llamar el Canónigo, ò Prebendado de alguna Catedral ò Colegial”. Diccionario de autoridades, s. v., t. I (1726).

${ }^{15}$ Partido: "Se llama también el distrito o territorio, que está comprehendido de alguna jurisdicción o administración de una Ciudad principal”. Diccionario de autoridades, s. v., t. v (1737).

16 "Relación de méritos y servicios del Dr. Jacinto de la Serna", AGI, Indiferente, v. 194, n. 4 , f. 1 r.

${ }^{17}$ Capellanía: "Institución hecha con autoridad del Juez Ordinario Eclesiástico, y fundación de renta competente, con obligación de Misas, y algunas con asistencia a las Horas Canónicas". Diccionario de autoridades, s. v., t. II (1729).

18 "Pedimento hecho por el Dr. Jacinto de la Serna sobre ser declarado capellán de la capellanía de Rodrigo de Vargas”, AGN, Bienes Nacionales, v. 885, exp. 2. 
un título honorario de doctor en 1632, lo que se dio a conocer por un edicto del arzobispo Francisco Manso de Zúñiga, quien dice ser su familiar. ${ }^{19}$

Después de pasar varios años como párroco de pueblos de indios en Tenancingo y Xalatlaco, fue trasladado a la Catedral Metropolitana. Entre los cargos que ocupó, una vez que se trasladó a la catedral, destacan el de "Visitador General y examinador general y sinodal de suficiencia y lenguas". También se desempeñó como cónsul en la chantría de Guadalajara. ${ }^{20}$ Nuestro personaje trabajó como censor de libros y su nombre se puede leer en varios textos, uno de ellos es el Confesionario de Bartolomé de Alva, en el que el entonces arzobispo Francisco Manzo y Zúñiga señala que el texto fue enviado al doctor Jacinto de la Serna, visitador general, y al padre Juan de Ledesma, lector de Teología de la Compañía de Jesús. La aprobación de Jacinto de la Serna está fechada en Xalatlaco el 20 de julio de $1634 .{ }^{21}$ En 1654, Jacinto de la Serna solicitó que se le otorgara una dignidad en la Catedral Metropolitana de México, para lo que envió una relación de méritos que estaba respaldada por el arzobispo, el virrey y algunos representantes de las órdenes religiosas de dicha ciudad. Dicha dignidad, una ración, ${ }^{22}$ se le entregó en $1659 .{ }^{23}$ En 1660 escribió al rey Felipe IV para agradecerle por la ración que le había otorgado en 1659 y también para solicitarle una canonjía ${ }^{24}$ que se encontraba vaca en la catedral metropolitana. ${ }^{25}$ Esto es importante porque los dos cargos no podían mezclarse, pues desde la constitución del obispado de

19 "Edicto del arzobispo de México Francisco Manso de Zúñiga, concediendo grado doctoral honorario a familiar suyo, el Licenciado Jacinto de la Serna”, AGI, México, caja 31, exp. 11.

20 "Relación de méritos y servicios del Dr. Jacinto de la Serna”, AGI, Indiferente, v. 194, n. 4 , f. 1 r.

${ }^{21}$ Bartolomé de Alva, Confessionario mayor y menor en lengua mexicana. Y platicas contra las supersticiones de idolatria, que el dia de oy an quedado a los Naturales desta Nueva Espa$\tilde{n} a$, e instricion de los Santos Sacramentos (México: Francisco Salbago, impresor del Secreto del Santo Officio, 1664).

${ }^{22}$ Ración: "En las Iglesias Catedrales o Colegiales es un Beneficio Eclesiástico, que da en el coro alguna preeminencia: como el Deán, Arcediano, Chantre. Y también se llama así la persona que goza el tal empleo". Diccionario de autoridades, s. v., t. III (1732).

${ }^{23}$ Dignidad: "Prebenda, en alguna Iglesia Catedral o Colegial, inmediata a los Canonicatos, y que tiene su renta en la mesa Canonical”. Diccionario de autoridades, s. v., t. v (1737).

${ }^{24}$ José Gabino Castillo Flores, El cabildo eclesiástico de México (1530-1612) (Zamora: El Colegio de Michoacán, 2018), 36-37. Una canonjía es "la Prebenda que goza el Canónigo, en alguna Iglesia Catedral o Colegial, con las rentas y emolumentos que le pertenecen por su asistencia y servicio. Diccionario de autoridades, s. v., t. III (1729).

25 "Carta de Jacinto de la Serna al rey Felipe IV para obtener una segunda dignidad", AGI, Cartas de Audiencia, México, n. 83, f. 1r. 
México, fray Juan de Zumárraga estableció que las canonjías no podían mezclarse con otras dignidades. Dicha solicitud la hacía porque decía tener muchas deudas y que con lo de la ración no le alcanzaba para solventarlas; la carta la firmó como capellán, ${ }^{26}$ y fue revisada por la Audiencia del rey y se agregó una nota en la que dice que no se encontró una respuesta en la que el virrey diga que aceptó que se le entregara también la canonjía. ${ }^{27}$

El doctor Jacinto de la Serna fue rector de la Real y Pontificia Universidad de México en tres ocasiones. Esto lo señaló él mismo en la portada del Manual de ministros y en la relación de méritos que envió al rey en 1654. La evidencia de archivo sólo nos da noticia de dos ocasiones, la primera en noviembre de 1642, que señala que el 11 de noviembre de ese año hizo juramento como rector de la Real y Pontificia Universidad de México. ${ }^{28} \mathrm{La}$ segunda es del 11 de noviembre 1650 cuando presentó el juramento al cargo de rector. ${ }^{29}$ De acuerdo con Alberto María Carreño, Jacinto de la Serna era rector en octubre de 1642 y fue reelecto en noviembre de ese año, con lo cual se cumplirían los tres periodos. La información de Carreño es a partir de los libros de claustros de la Real y Pontificia Universidad de México. ${ }^{30}$ Sin embargo, no sabemos desde cuándo inició su primer rectorado. Tuvo a su cargo varias cátedras, entre ellas la de Teología. Además, fue miembro de la junta de gobierno durante varios periodos.

Sabemos que el manual debió escribirse en algún momento entre 1650 y 1655, ya que Serna hace referencia a 1646, cuando estaba en una comisión en Atenango del Río por orden del arzobispo Mañozca, y dice "no haber tenido entonces intención de hacer este tratado". ${ }^{31}$ Más adelante habla del

26 "Carta de Jacinto de la Serna al rey Felipe IV para obtener una segunda dignidad", AGI, Cartas de Audiencia, México, n. 83, f. 1r. Capellán: "El que goza renta Eclesiástica por razón o título de Capellanía”. Diccionario de autoridades, s. v., t. II (1729).

27 "Carta de Jacinto de la Serna al rey Felipe IV para obtener una segunda dignidad", Cartas de Audiencia, México, n. 83, f. 2v.

28 "Acta del claustro celebrado el 11 de noviembre, en el que se refiere: el juramento que hizo el nuevo rector doctor Jacinto de la Serna y de los consiliarios, electo el 10 de noviembre anterior", AGN, Universidad, v. 12, exp. 12.

29 "Juramento del rector Jacinto de la Serna y de los consiliarios electos el 10 de noviembre", AGN, Universidad, v. 14, exp. 33.

${ }^{30}$ Alberto María Carreño, Efemérides de la Real y Pontificia Universidad de México según sus libros de claustros (México: Universidad Nacional Autónoma de México, Instituto de Investigaciones Históricas, 1963), t. I, 196.

${ }^{31}$ Jacinto de la Serna, "Manual de ministros de indios para el conocimiento de sus idolatrías, y extirpación de ellas”, Anales del Museo Nacional (México: Imprenta del Museo Nacional, 1892), t. VI, 294. Por la facilidad de lectura se utilizó esta versión. 
año 1650 en pasado. La obra está dedicada al recién llegado arzobispo Matheo de Zaga de Bugueiro, que ocupó el cargo de 1655 a 1662.

Jacinto de la Serna murió en 1661, sin ver su obra publicada. El nombre completo del manuscrito era Manual de ministros de indios para el conocimiento de sus idolatrías, y extirpación de ellas. ${ }^{32}$ Es probable que el manual no llegara a la imprenta en su tiempo porque, como dice Viviana Díaz Balsera, los arzobispos a los que iban dedicadas las obras de Serna y Ruiz de Alarcón consideraron que trataban de "prácticas supersticiosas que, aunque reconocidamente generalizadas, no amenazaban con derrocar al cristianismo". ${ }^{33}$ Se conocen tres manuscritos: uno que se encuentra en la Biblioteca del Nacional de Antropología e Historia en la ciudad de México, uno que se encuentra en la Biblioteca Nacional de España y el de la Biblioteca de la Hispanic Society en Nueva York.

Finalmente, don Joaquín García Icazbalceta la publicó por primera vez en los Anales del Museo Nacional en 1892. Las ediciones posteriores han sido publicadas sin cambios de la edición del siglo xIX y, a pesar de las múltiples referencias a la obra, no existe una edición crítica.

El Manual de ministros es una obra emparentada con otros dos trabajos de la época: el Tratado de las costumbres gentílicas de Hernando Ruiz de Alarcón ${ }^{34}$ y la Breve relación de idolatrías de Pedro Ponce de León. ${ }^{35}$ Ambos textos tuvieron una gran influencia en la obra de Jacinto de la Serna. Podría decirse que los textos de Ruiz de Alarcón y de Ponce de León fueron el referente etnográfico que usó Serna para construir una obra de un alto calado intelectual. Serna se apoya en ambos textos que fueron producto del profundo conocimiento de los rituales indígenas y del idioma de sus autores. También es importante la detallada descripción de los calendarios mexicas, tonalpohualli (ritual de 260 días) y el xihuitl (solar de 360 días),

${ }^{32}$ Para más información sobre el manuscrito de Jacinto de la Serna, véase Valdés Borja, “Jacinto de la Serna”, 1436-1439.

${ }_{33}$ Viviana Díaz Balsera, Guardian of Idolatry. Gods, Demons, and Priests in Hernando Ruiz de Alarcón's Treatise on the Heathen Superstitions (Norman: Oklahoma University Press, 2018), 40 .

${ }^{34}$ Este libro ha recibido más atención y cuenta con dos ediciones en inglés. La primera de 1982 a cargo de Michael Coe y Gordon Whittaker, Aztec Sorcerers in Seventeenth Century Mexico. The Treatise on Superstitions by Hernando Ruiz de Alarcón (Albany: Institute for Mesoamerican Studies, State University of New York, 1982). Otra de 1984: Richard Andrews y Ross Hassig, Treatise of the Treatise on the Heathen Superstitions that Today Live Among the Indians Native to This New Spain, 1629 (Norman: Oklahoma University Press, 1987).

${ }^{35}$ Estas obras también aparecieron en el mismo volumen de los Anales del Museo Nacional de 1892. 
que incluye ilustraciones, y que salvo por los estudios de David Tavárez, no ha recibido la atención debida. ${ }^{36}$ De acuerdo con David Tavárez, el Manual de ministros también estuvo influenciado por la obra de Martín de León, Camino del cielo. ${ }^{37}$

El texto del Manual de ministros bien podría considerarse como una obra de teología indiana. Está hecha para demostrar que algunas de las antiguas creencias y prácticas religiosas de los indios no habían sido eliminadas y que había en ellos una idolatría de tipo pernicioso. El Manual de ministros es un texto que propone que la idolatría de los indios es dañina y no se debe a simple ignorancia, como se pretende en otras obras que se escribieron en el mismo contexto. Aquí ya no se ve al indio como al ignorante que no tuvo la oportunidad de conocer a Dios, sino como al que, a pesar de haber tenido la oportunidad de reconocer a Dios, no lo recibió como debía y en su lugar mezcló costumbres antiguas con cultos cristianos, lo que convertía a la idolatría en una práctica muy perjudicial.

La idolatría en el Manual de ministros se desarrolló en tres ejes, uno teológico, uno etnográfico y uno jurídico. En la introducción es en donde se expone el aspecto teológico; en el desarrollo del trabajo se encuentra la parte etnográfica, en la que el autor explica más la propuesta de la idolatría como enfermedad, y el último de los capítulos, que bien podríamos decir que es la conclusión, trata la idolatría desde la perspectiva jurídica.

Jacinto de la Serna no veía en la idolatría una pervivencia intacta de las prácticas religiosas de los indios, sino la fusión de esas prácticas con las formas religiosas cristianas. Si bien los indígenas no eran católicos en un sentido ortodoxo, tampoco tenían las estructuras socioculturales que les permitieran pervivir en la antigua religión. En todo caso, tuvieron la suficiente resiliencia para adaptarse a las circunstancias del dominio español y mantener algunos elementos muy representativos de las antiguas culturas al lado de los modos cristianos.

Las ideas de Jacinto de la Serna están basadas en textos veterotestamentarios y en neotestamentarios, así como en los escritos de Padres de la Iglesia y otros autores importantes en la tradición teológica. Además, está apoyado en otros textos de filosofía clásica y cuenta con ejemplos de su realidad novohispana. Cuando estamos frente al Manual de ministros, nos

36 Tavárez, Las guerras invisibles, 167-169.

37 Tavárez, Las guerras invisibles, 165. 
encontramos frente a un libro erudito, cuyo autor abrevó de una variedad muy amplia de fuentes.

El Manual de ministros está dedicado a Matheo de Zaga de Bugueiro, quien, como se mencionó, fuera arzobispo de México de 1655 a 1662. Después de su paso por Nueva España regresó a Europa, donde fungió como obispo de Cádiz, luego de León y finalmente de Cartagena, España. En su trabajo como arzobispo de México debió tener un trato cercano con Jacinto de la Serna.

En el prólogo de la obra se manifiesta que está dirigida a los beneficiados y ministros de doctrinas de indios. Recordemos que el mismo autor fue un beneficiado de pueblos de indios. Serna es muy enfático en señalar la labor que realizaban dichos personajes: la consideraba como fundamental para la Iglesia, pues a través del evangelio se daba "la destrucción de la idolatría". ${ }^{38}$ Invitaba a los religiosos a que pensaran en que el trabajo que desempeñaban era en favor de Dios y no de los hombres y, por lo tanto, se tenía que hacer con mucho cuidado. Las palabras dirigidas a los religiosos son combinadas con algunas citas bíblicas para reforzar los argumentos; así, por ejemplo, cita el libro de los Jueces para hacerles saber a los doctrineros que su trabajo requería de mucho cuidado en las decisiones que se tomaban.

Como ya anunciábamos antes, las fuentes utilizadas por Jacinto de la Serna en su Manual de ministros son muy amplias y variadas. Éstas incluyen a los teólogos más representativos de la Iglesia, como Agustín de Hipona y Tomás de Aquino, además de otros teólogos importantes, de tiempos más cercanos al autor. Asimismo, incluye autores griegos y latinos como Plinio el Viejo con el Panegírico del emperador Trajano, Galeno y su Methodo medendi y Sanitate, Hipócrates y el In officio cirugie y Marco Tulio Cicerón con De oficiis. La lista de autores cristianos es también muy abundante y entre ellos se encuentran Cornelius Jansenus, Vicencio Lirense, Bernardo de Claraval, Joannes Chrysostomus y Carlo Martam, entre otros. También se encuentran los autores novohispanos contemporáneos de Serna; al que más cita es a Juan de Torquemada con su Monarquía indiana y de sobra conocidas son las citas de Hernando Ruiz de Alarcón y Pedro Ponce, además de que también hace referencia a información obtenida por pláticas con otros religiosos que le compartieron sus anécdotas y experiencias con indios idólatras.

\footnotetext{
${ }^{38}$ Serna, "Manual de ministros", 269.
} 
Un estudio crítico de las fuentes sería importante porque daría más información sobre la historia intelectual de Jacinto de la Serna; no lo haremos aquí porque nos distraería de nuestro objetivo principal. Sin embargo, nos pareció importante hacer una breve lista de algunos de los autores que cita en su obra.

\section{La idolatría en el Manual de ministros}

La idolatría en el contexto en el que escribió Jacinto de la Serna se debe ver en términos de lo que los religiosos esperaban de los indígenas en sus comportamientos. Es decir, de lo bueno y lo malo, de lo correcto y lo incorrecto que, de acuerdo con Serna y otros autores, eran conceptos que los indígenas ya debían tener interiorizados y saber distinguirlos desde la visión del cristianismo.

Jacinto de la Serna propone tres formas de la idolatría. La primera forma era la perspectiva teológica, que se presentó como el culto inadecuado o pervertido a Dios, que lleva a la adoración de criaturas. La segunda forma de idolatría, que era la enfermedad, se presenta en la etnografía recogida por él y por las fuentes consultadas. Finalmente, la idolatría podía derivar en un crimen y en dicha obra se proponían las medidas adecuadas para proceder contra los indios idólatras. Detrás de las tres formas de idolatría que se presentan en el Manual de ministros se encuentra la íntima relación de la idolatría con lo demoniaco; es decir, la idolatría era considerada una manifestación del Diablo entre las personas, con el objeto de ganar seguidores.

\section{La idolatría en la perspectiva teológica}

Uno de los aspectos más importantes en esta obra es que podemos considerar que en su conjunto hay una amplia definición de la idolatría y de sus formas. La primera parte define la idolatría a partir de pasajes bíblicos, en su mayoría del Antiguo testamento, y es que es allí donde el concepto se fija como una transgresión a la ley establecida después del acuerdo de reconocimiento de Dios como única deidad del pueblo de Israel. ${ }^{39}$

\footnotetext{
${ }^{39}$ Remitimos al lector interesado en el concepto de idolatría en un contexto más amplio a Moshe Halbertal y Avishai Margalit, Idolatría. Guerra por imágenes: las raíces de un conflicto milenario (Barcelona: Gedisa, 2003), así como a Carmen Bernand y Serge Gruzinski, De
} 
Al menos en tres partes del texto se encuentran presentes definiciones como tal de idolatría. Las primeras dos son muy breves, mientras que en la tercera hay una amplia exposición del concepto y es donde se refiere al aspecto jurídico. En las primeras dos definiciones el común denominador es el culto que se debería dar a Dios pero que se dirige a objetos, animales o personas. La tercera definición, parte de la consideración de la idolatría como un crimen y la veremos en el último apartado de este trabajo. En primer lugar, se señala que es un pecado que se daba por "la honra que defraudan a su Divina Magestad y se la dan a otras criaturas". ${ }^{40}$ Para fortalecer el argumento, utiliza el pasaje 32 del Éxodo, donde se hace referencia al becerro de oro que adoraban los israelitas y al castigo que recibieron por ello. Más adelante señala que los indios eran lobos vestidos de ovejas, "siendo en el interior robadores de la honra debida a Dios, atribuyéndola a las criaturas y en ellas al Demonio". ${ }^{41}$ El libro del Éxodo resulta fundamental para entender la idolatría, ya que en él se presentó la ley de Dios al pueblo de Israel y es también el libro en el que se estableció el pacto de reconocer a Yahvé como única deidad y con ello lograr que los liberaran de Egipto y llegaran a la tierra prometida. Dicho acuerdo tenía ciertas reglas: los mandamientos. La primera de ellas señalada por el propio Dios en el Éxodo 20:3, "No tendrás dioses ajenos delante de mí".

Para empezar, Jacinto de la Serna señala, apoyado en Bernardo de Claraval, que existen tres tipos de personas en relación con Dios: unas que no buscan a Dios y tampoco éste las busca, otras que lo buscan y lo encuentran y generan una relación constante de intercambio, y, finalmente, otras que, a pesar de ser incluidas en la cristiandad, rechazan a Dios y "apostatan su divina Ley”. ${ }^{42}$ Los indios son considerados en este último grupo. No obstante esa filiación en la que los coloca, Serna destaca que eran como los romanos en su multiplicidad de deidades y la manera en que adoptaban dioses de otros pueblos, además de dejar a los suyos en los intercambios que hacían. Esto también traiciona el pacto establecido entre el pueblo de Israel y Dios, en el que sólo le rendirían culto a él y no a otro dios y que queda de manifiesto en el Éxodo y en el Levítico: en ambos, Dios les dice a los israelitas que no harán estatuas de otros dioses (véase Éxodo 20:4 y Levítico 26:1).

idolatría. Una arqueología de las ciencias religiosas (México: Fondo de Cultura Económica, 1992).

${ }^{40}$ Serna, "Manual de ministros", 274.

${ }^{41}$ Serna, "Manual de ministros", 279.

${ }^{42}$ Serna, "Manual de ministros", 277. 
Eran dos cosas las que Jacinto de la Serna pretendía resaltar sobre la idolatría. En primer lugar, la existencia de un solo Dios. En segundo lugar, que había un culto que seguir y que, si éste se corrompía, se caía en idolatría. De acuerdo con los postulados judeocristianos, el ídolo es un objeto creado por las manos de alguna persona; por eso, no puede ser un dios. Las referencias a objetos que reciben culto divino están en varios pasajes bíblicos; en ellos se alude a la prohibición, pero también a las consecuencias de participar en los cultos: "La idolatría puede ser múltiple y variada, su núcleo central es que nada humano, ninguna creencia y ningún objeto pueda volverse absoluto". ${ }^{43}$ La idolatría se consideraba un pecado por la representación errónea de Dios, o el culto dirigido a objetos de manufactura humana. Además, la idolatría era peligrosa porque implicaba una rebeldía contra un contrato establecido, es decir la falta de reconocimiento de Dios como autoridad suprema.

Podemos ver que para Jacinto de la Serna había una íntima relación en la manera de entender la idolatría y el mal. Para Serna, la idolatría era ante todo un pecado. Este pecado era considerado grave, pues los indios tenían el conocimiento, aunque fuera básico, de las reglas de la Iglesia católica. Es por ello que nuestro autor también considera a la idolatría como causa y consecuencia de los males de los indios, incluso insinúa que la inundación de la ciudad de México de 1629 pudo ser por la idolatría de los indios, ${ }^{44}$ idea que va en la misma línea de lo que Motolinía dice en la carta que envió a Carlos V, en la que señala que el origen de los males de los indios era la idolatría y que, por ello, padecieron de epidemias como castigo divino. ${ }^{45}$ Esta era también la idea que imperaba en la población de ese momento.

De acuerdo con Jacinto de la Serna, todo empezaba por un mal de origen ético, como los malos pensamientos que derivaban en comportamientos incorrectos, como los que él menciona, que eran practicar los antiguos rituales religiosos o mezclarlos con los católicos, resguardar antiguos dioses, participar en ceremonias de curación o utilizar las medicinas mágicas. Al no ser corregidos dichos comportamientos, éstos llevan a males físicos, como enfermedades, epidemias o incluso a la condición de sometimiento en la

${ }^{43}$ Roger Calles, “Epílogo”, en Martin Buber, Imágenes del bien y del mal (Buenos Aires: Lilmod, 2006), 238.

${ }^{44}$ Serna, "Manual de ministros", 287.

${ }^{45}$ Motolinía (fray Toribio de Benavente), "Carta al rey de España”, en Colección de documentos para la historia de México, ed. de Joaquín García Icazbalceta (México: Librería de J. M. Andrade, 1858), t. I, 274. 
que vivían los indios bajo el dominio español. ${ }^{46}$ Más adelante, el religioso continúa con este argumento y señala que los indios viven en esa condición de servidumbre por su pasado, ya que "habiendo Dios nuestro señor hécholos tan prósperos, y señores en su gentilidad; por sus inhumanidades, crueldades y sacrificios de hombres, los sujetó a tantos trabajos, y a que no trabajasen tanto para sí, como para otros". ${ }^{47}$

Las consecuencias del comportamiento de los indios no eran un asunto menor, pues en una sociedad como la novohispana del siglo XVII o en una sociedad de tradición judeocristiana, el que un individuo tuviera comportamientos incorrectos, ética y moralmente hablando, tenía una repercusión en la sociedad en general, pues la ira de Dios podía recaer sobre todos, sin distinción entre el causante de las ofensas divinas y el inocente. De acuerdo con la visión ortodoxa cristiana, los indios debían seguir las normas y los postulados católicos, porque de no hacerlo podían hacerse acreedores a consecuencias negativas por parte de Dios.

A pesar de esas concepciones de la idolatría y los indios, para Jacinto de la Serna, los indios tenían un papel muy importante dentro del funcionamiento del imperio español y al respecto dice que eran la sangre que mantenía en movimiento al imperio. Eran una

nación tan útil a la vida política de esta Monarquía de España y que en ella dependen de su conservación, porque todos viven eslabonados con el trabajo de estos, porque en la corriente del tiempo presente no ay cosa que se pueda obrar sin ellos, ni las minas, ni las mieses, ni las fábricas de los edificios, porque son la sangre del cuerpo de la mística de la Monarquía. ${ }^{48}$

Era importante mantener el orden en los indios, pues su desorden podría provocar el resquebrajamiento del imperio.

Serna hace referencia a ese pacto que se hizo de reconocer a Dios como el único y verdadero que se acordó con los indios para ser parte de la ecúmene católica, pero que no estaban cumpliendo. ${ }^{49}$ Llama la atención que Serna no utilice el concepto de pacto para referirse al acuerdo entre las

${ }^{46}$ Serna, "Manual de ministros", 287.

${ }^{47}$ Serna, "Manual de ministros", 428.

${ }^{48}$ Serna, “Manual de ministros”, 287. David Tavárez ofrece una interesante explicación, basado en el trabajo de Ernest Kantorowicz, The King's Two Bodies. Tavárez sostiene que hubo un cambio radical en la interpretación de la idolatría porque se incluía a los indios en el cuerpo político de la monarquía hispana. Tavárez, Las guerras invisibles, 502-503.

${ }^{49}$ Serna, "Manual de ministros", 279. 
personas y Dios, pero sí para el pacto demoniaco, del cual refiere varios ejemplos. La idolatría que imperaba entre los indios era una prueba de ese incumplimiento de la reverencia que le debían a Dios y se la daban a otros dioses y, por ello, señalaba que los indios del siglo xvir eran más maliciosos que los del siglo anterior, pues ya debían saber distinguir al Dios verdadero del falso. Aun así, consideraba que antes de reprender era necesario educar a los indios en la fe, es decir, evangelizar y continuar con esa función que los religiosos habían descuidado con el paso del tiempo. Esa era la finalidad de su texto: que sirviera como un instrumento pastoral en el que se reconocieran los comportamientos desviados de la ortodoxia que realizaban los indios. "El cura de este mal que hoy padecen los indios en sus idolatrías, han de procurar los ministros de estos tiempos hacer ventaja a los antiguos padres, no en enseñarles otra cosa de lo que les enseñaron; sino en procurar declararles su sancta doctrina, muy en particular a el mal que se reconoce en ellos." ${ }^{50}$ Lo que vemos es que, si la idolatría era una enfermedad, entonces había un remedio, una forma de contrarrestar los efectos dañinos y restaurar la salud. La constante supervisión de los indios era necesaria para que no cayeran en la enfermedad de la idolatría, más que una medicina para combatir la enfermedad era una prevención.

\section{Etnografía de la idolatría}

El texto de Jacinto de la Serna cuenta con mucha información que se recogió de manera oral de otros religiosos y la que él mismo vio y conoció de primera mano. Se puede apreciar mucho del comportamiento cotidiano en los pueblos de indios para las actividades diarias. Algo que llama mucho la atención es que sugiere que hubo una campaña para mantener los antiguos conocimientos religiosos, o una campaña en favor de la idolatría. Esto habría sucedido en la década de 1610. Lo anterior fue referido por Pedro Ponce de León, beneficiado de Zumpahuacán, quien, de acuerdo con la información relatada, señalaba que habrían salido algunos maestros de idolatría por la zona del valle de Toluca para "infestarla y refrescar la memoria de todos para que ni se olvidasen de sus dioses, ni de sus ceremonias". ${ }^{51}$ David Tavárez ofrece un profundo análisis de la campaña realizada por Pedro Ponce. ${ }^{52}$

50 Serna, "Manual de ministros", 272.

${ }^{51}$ Serna, "Manual de ministros", 288.

52 Tavárez, Las guerras invisibles, 135-137. 
Lo relatado por Ponce de León nos da una idea de que lo que se conoce por la documentación resguardada en el Archivo General de la Nación y otras causas y procesos en otros archivos locales, ya sean civiles o eclesiásticos, representan sólo una parte de lo que pudo ser una especie de campaña antiidolátrica en el arzobispado de México en las primeras décadas del siglo XVII. Recordemos que el Concilio Tercero Provincial Mexicano proveyó de varias herramientas para poder atender los asuntos de justicia religiosa de los indios. En algunos casos eran atendidos por tribunales locales; en otros, por los obispos en las visitas que hacían, y en otros, desde luego, por la justicia civil que también tenía injerencia sobre la idolatría, pues este era un crimen del fuero mixto. ${ }^{53}$

Una de las explicaciones que más argumenta Serna es la de la idolatría como una enfermedad en el alma de los indios; para eliminarla, era necesario reconocerla, como hacen los médicos con las enfermedades, y saber la etiología de la enfermedad para así dar un tratamiento o encontrar un remedio a ese padecimiento.

Esta idea de idolatría como un padecimiento la argumenta a través de Galeno y se vale del Methodo medendi para señalar que "no se puede curar el enfermo, si primero no se conoce la enfermedad: así los médicos espirituales de Indios han de ser científicos, y provectos en ciencia, y en el idioma de su lengua, y nación de los indios, que administran". ${ }^{54}$ Tal consideración, común en los textos posconciliares, ya aparecía en el prólogo de la Historia general de las cosas de la Nueva España; en ella Sahagún hace ese mismo señalamiento y menciona que la cura de la idolatría era la enseñanza de la doctrina. ${ }^{55}$ Esta es la concepción imperante de la idolatría durante el siglo XVII, por lo menos para la América española. ${ }^{56}$

La idolatría como enfermedad es la idea que el autor desarrolla de manera más amplia y en la que incluye información etnográfica muy rica,

${ }^{53}$ Gerardo Lara Cisneros, ¿Ignorancia invencible? Superstición e idolatría ante el Provisorato de Indios y Chinos del Arzobispado de México en el siglo XVIII (México: Universidad Nacional Autónoma de México, Instituto de Investigaciones Históricas, 2016), 127-141.

${ }^{54}$ Serna, "Manual de ministros", 273.

${ }^{55}$ Bernandino de Sahagún, Historia general de las cosas de la Nueva España (México: Consejo Nacional para la Cultura y las Artes, 2000), 61.

${ }^{56}$ Juan Carlos García Cabrera, “¿Idólatras congénitos o indios sin doctrina? Dos comprensiones divergentes sobre la idolatría andina en el siglo Xviı”, en Los indios ante los foros de justicia religiosa en la Hispanoamérica virreinal, coord. de Jorge E. Traslosheros y Ana de Zaballa Beascoechea (México: Universidad Nacional Autónoma de México, Instituto de Investigaciones Históricas, 2010), 109. 
la cual tomó de su experiencia y de otros autores, entre ellos, Ruiz de Alarcón y Ponce de León, que ya hemos referido. En el Manual de ministros se presenta a los médicos indígenas, titicih en náhuatl, como personajes nocivos para los pueblos de indios, pues en ellos recaía el antiguo conocimiento de elementos como el calendario o las creencias del origen de las enfermedades no naturales. Además, no sólo eran encargados de vigilar la salud, también eran capaces de provocar enfermedad. Eran una serie de personajes con la capacidad de manipular lo sagrado, que de acuerdo con Alfredo López Austin serían alrededor de 40 tipos distintos, en su mayoría eran médicos y otros estaban especializados en provocar el mal, como el tlacatecólotl. No todos están incluidos en el Manual, aunque sí una cantidad importante. ${ }^{57}$ Se debe destacar que Serna, a diferencia de Sahagún, no hace una diferenciación dicotómica entre buenos y malos: consideró que todos los especialistas tenían la facultad de actuar de forma generosa o en perjuicio de las personas.

Serna tenía un particular interés en las prácticas médicas de los indios y la preocupación de que éstos desconfiaran de los médicos españoles como quedó de manifiesto en una carta que Serna escribió al arzobispo Manzo y Zúñiga en 1636. Esto se encuentra en el contexto de epidemias que azotaron el centro de México en la década de 1630 y que generó que los médicos indígenas tuvieran una demanda mayor. ${ }^{58}$ Además, consideraba que muchos de los males se podían curar a través de la fe y las medicinas que incluían el uso de reliquias religiosas, como en su propuesta del uso de los huesos de Gregorio López. De acuerdo con Serna, él mismo lo había probado con una india aquejada por una gran enfermedad gastrointestinal, a la que le dio una cucharada de hueso del santo. ${ }^{59}$

Los médicos indígenas eran para Jacinto de la Serna los que cuidaban que se cumplieran prácticas religiosas que no eran de tradición cristiana y por ello señalaba que "Los médicos y médicas son los más perjudiciales y principales celadores de estas idolatrías". ${ }^{60}$ Más adelante escribía: "Este nombre tícitl comúnmente se reputa y corresponde a lo que en nuestro vulgar castellano se llama 'médico' y entre los indios tiene más significaciones; pues significa en la aceptación de ellos 'adivino,

${ }^{57}$ Alfredo López Austin, “Cuarenta clases de magos en el mundo náhuatl”, Estudios de Cultura Náhuatl, n. 7 (1967): 87-117.

58 Tavárez, Las guerras invisibles, 163-164.

59 Serna, "Manual de ministros", 301-302.

${ }^{60}$ Serna, "Manual de ministros", 284. 
sabio y hechicero', y que tiene pacto con el Demonio". ${ }^{61}$ Cabe señalar que la mayoría de los indios que llegaban a un foro de justicia eclesiástica era por asuntos práctica médica. ${ }^{62}$

Serna seguía la propuesta de Bernandino de Sahagún, quien en el prólogo de la Historia general señalaba que: "Los predicadores y confesores, médicos son de las ánimas; para curar las enfermedades espirituales conviene espertia de las enfermedades espirituales". ${ }^{63}$ De la misma manera, Serna señalaba que "no hay oficio más á el vivo representado en el médico, o cirujano corporal, que el del médico espiritual, y cura de almas". ${ }^{64}$ Por ello, invitaba a los religiosos a conocer las enfermedades del alma, las cuales se podían identificar a través de las palabras de los indios; por esto, señalaba Serna que era importante conocer bien las lenguas indígenas.

En la carta del jesuita Marcos de Irala destaca la importancia de la obra y señalaba que:

Y si este nombre Médico se deriva de un vocablo griego, que quiere decir experiencia [...] quien tantas tienen de las dolencias espirituales de estos miserables indios, bien podrá haciendo oficio de Médico espiritual de sus almas, recetar los remedios tan cristianos, prudentes, y ajustados, que en el discurso de esta obra se proponen. ${ }^{65}$

Consideramos que los remedios prudentes son aquellos que Serna propone para reforzar la enseñanza del evangelio antes de llegar a la impartición de justicia, por lo que insiste en que los curas de indios debían ser expertos en lenguas. Para Serna, esto era muy importante porque a partir de que los religiosos conocieran muy bien la lengua de los indios podrían saber si realizaban actos idolátricos o no. Era a través del habla que se daría remedio a los indios que requirieran curarse del padecimiento de la enfermedad de la idolatría. Por ello, señalaba que "poco importa que un ministro sea eminente en ciencia si no sabe la lengua de los indios a quienes ha de administrar y con quien ha de tratar para entenderlos". ${ }^{66}$

El conocimiento de las lenguas indígenas no era una preocupación sólo de Jacinto de la Serna; el Concilio Tercero Provincial Mexicano hizo varios señalamientos sobre la necesidad de que los religiosos las aprendieran.

${ }^{61}$ Serna, "Manual de ministros", 304.

${ }^{62}$ Griffiths, La cruz y la serpiente, 131.

${ }^{63}$ Sahagún, Historia general, 61.

${ }^{64}$ Serna, "Manual de ministros", 273.

${ }^{65}$ Serna, "Manual de ministros", 477.

${ }^{66}$ Serna, "Manual de ministros”, 273. 
El decreto tercero, "De la doctrina cristiana que se ha de enseñar a los párvulos”, que es parte del Libro primero, señalaba, entre otras cosas, que: "se encarga a los prelados que con toda brevedad procuren que se traduzcan [las doctrinas] en aquellas lenguas de indios que cada uno en su diócesis viere que son más comunes y más necesarias". ${ }^{67}$ Mientras que en los archivos se pueden encontrar convocatorias para ocupar beneficios eclesiásticos en las que se señala como requisito demostrar el conocimiento de las lenguas indígenas. Por ejemplo, la convocatoria de 1654 en la que se invitaba a los religiosos a participar en la selección para beneficios vacantes y uno de los elementos más importantes de la selección era el conocimiento de las lenguas. ${ }^{68}$

Es en este apartado en el que se puede notar que lo que para Jacinto de la Serna era idolatría, para los indios era una forma de entender lo sagrado y su manipulación. En una perspectiva ortodoxa, la Iglesia católica y sus miembros eran los únicos capacitados para manipular lo sagrado y, por lo tanto, los cultos realizados por los indios no eran lícitos.

\section{Idolatría y justicia eclesiástica}

Es hacia el final del Manual de ministros en donde el autor retoma la idolatría desde la teología, para luego seguir con su vertiente jurídica. En el capítulo XXVIII, que se titula "De el remedio breve que todas estas materias piden, y lo mucho que le incumbe a nuestro rey, a sus virreyes y ministros el procurarlo", se encuentra la definición más amplia de idolatría. El autor echó mano de varios de los teólogos más destacados de la patrística, así como de una serie de pasajes bíblicos para definir el concepto. La idolatría es entendida por el doctor De la Serna como la adoración de falsos dioses, pero también como el culto indebido a Dios que podría derivar en crimen por el desconocimiento de la autoridad, por lo que era necesario que el idólatra enfrentara a la justicia.

En primer lugar, utiliza la Suma de teología de Tomás de Aquino para explicar la superstición y señalar que la idolatría es una de sus formas. Para ello cita el apartado II-II, cuestión 92, que es la parte en la que Tomás de

${ }^{67}$ Martínez Ferrer, Decretos del Concilio, v. II, 214.

68 "Edicto convocatorio para sacerdotes que sepan lenguas mexicana, otomí y demás", Archivo del Cabildo Catedral Metropolitano de México, Edictos, caja 1, exp. 38, 1654, f. 1r. 
Aquino desarrolla su propuesta de superstición; ahí señalaba que ésta se manifiesta en cuatro formas: la idolatría, la adivinación, los amuletos medicinales y las vanas observancias. Consideraba la superstición como un vicio opuesto a la religión por exceso, tal como aparece citado en el Manual de ministros. ${ }^{69}$ Lo que no está citado es la cuestión 94, pero se puede intuir que Serna se basó en ella al escribir que "es formal y verdadera idolatría, oponiéndose tan de veras a la veneración y culto divino, que a Dios nuestro señor se debe, que quitándolo de su divina y soberana majestad, lo ponen en los palos, en las piedras y en falsos y fingidos Dioses". ${ }^{70}$ Esto también está sustentado en el Deuteronomio 28:36, donde se hace referencia a las bendiciones por respetar la ley de Dios y a las maldiciones por no respetarla.

En la siguiente parte, Serna se refiere a la idolatría de los indios como algo pernicioso con que buscaban adorar a dos entidades distintas, por un lado, a Dios, y por otro, a sus antiguos dioses, quienes, de acuerdo con el autor, eran en realidad el demonio, que no quería retirarse de los indios y buscaba mantenerlos como sus fieles seguidores. De tal manera, Serna nos deja ver que la idolatría de los indios tenía un principio demoniaco y que los indios querían mezclar las cosas del Diablo con las cosas de Dios. Para armar este argumento, Jacinto de la Serna utiliza a Gregorio Magno con sus Morales, además de los comentarios que hizo Agustín de Hipona sobre el salmo 23 en La ciudad de Dios. Ambos autores concuerdan en que no se podía rendir culto a dioses diferentes. Lo que trata de señalar Serna es que los indios trataban de aparentar que eran católicos mientras mantenían antiguos cultos o bien dichos cultos convivían con las formas cristianas. Estaba convencido de que la fe de los indios era frágil y que no sólo mantenían cultos antiguos, sino que podían incorporar nuevos dioses a los ya existentes. "Bien podemos entender esto de estos indios, pues tienen tanta diversidad de pareceres, y son de ánimo tan flacos, que fácilmente lo convierten ya a una superstición, y ya a otra". ${ }^{71}$

La idolatría como crimen que debía ser castigado es también un asunto que se atendió en el Manual de ministros. Decíamos antes que la idolatría era considerada por Jacinto de la Serna como un pecado muy grave, pero también que pasaba del pecado al delito y que por lo tanto necesitaba de un castigo. Señalamos que cuando la idolatría no era tan nociva, con la predicación bas-

\footnotetext{
${ }^{69}$ Serna, "Manual de ministros", 448.

70 Serna, "Manual de ministros", 449.

${ }^{71}$ Serna, "Manual de ministros", 449.
} 
taba como un remedio a ella, por eso la noción de enfermedad. Pero, cuando trascendía más allá de los espacios personales, como un mal ejemplo de comportamiento, era cuando se convertía en un delito ${ }^{72} \mathrm{y}$, por lo tanto, era necesaria la incorporación de medidas más fuertes que la predicación. Es decir, cuando la idolatría se convertía en algo de dominio público se convertía en un delito y pasaba de la noción de enfermedad a la de crimen.

Jorge Traslosheros indica que "el paso entre el pecado ${ }^{73}$ individual que compete al foro de la conciencia y un crimen a ser atentado en el foro judicial está dado por la condición escandalosa de la conducta”. ${ }^{74}$ La idolatría era un delito porque implicaba un desconocimiento de la autoridad de Dios y esto llevaba al desconocimiento de sus representantes, tanto de las autoridades civiles como religiosas. Por delito entenderemos "cualquier acción que atenta contra el sistema normativo vigente, y por ello detectada, perseguida y castigada por una instrumentación determinada". ${ }^{75}$

Jacinto de la Serna proponía remedios para eliminar la idolatría, el más importante y eficaz sería la constante evangelización de los indios y de la carencia de instrucción no culpaba sólo a los indios, sino también a los religiosos por su poco compromiso. También señalaba que para los indios viejos este remedio no podía asegurar el éxito, pues era más difícil desarraigarles sus creencias; en estos casos era necesario que hubiera una aplicación de justicia eclesiástica. Consideraba indispensable la participación de los jueces de comisión para enmendar a los indios descarriados. ${ }^{76}$

La idolatría es presentada por Jacinto de la Serna como un crimen en diversas partes del Manual de ministros, tal como se ha señalado antes, pero de una manera contundente se hace en la parte final de la obra, en la que

72 Jorge Traslosheros, Iglesia, justicia y sociedad en la Nueva España. La Audiencia del Arzobispado de México 1528-1668 (México: Porrúa; México: Universidad Iberoamericana, 2004), 19.

${ }^{73}$ El pecado es por sí mismo un delito, ya que cometerlo implica romper una regla y la reparación implica el reconocimiento de una culpa que se expone en un foro de justicia que es el confesionario. La gravedad del pecado puede hacer que se cambie de ese foro de la conciencia que señala Jorge Traslosheros o bien que quede en el mismo foro. En el confesionario hay también un juez, que es el confesor, un acusado que es el confesante y hay una sentencia acorde con la gravedad del pecado, la cual implica una penitencia. Véase Michel Foucault, Obrar mal, decir la verdad. Función de la confesión en la justicia. Curso de Lovaina, 1981 (Buenos Aires: Siglo XXI, 2014), 200-204.

74 Traslosheros, Iglesia, justicia y sociedad, 92.

${ }^{75}$ Félix Segura Urra, "Raíces historiográficas y actualidad de la historia de la justicia y el crimen en la Baja Edad Media”, Anuario de Historia del Derecho Español, n. 7 (2003), 581.

${ }^{76}$ Serna, "Manual de ministros", 468. 
el autor citó el título cuatro del libro quinto del Concilio Tercero Provincial Mexicano de 1585, llamado "De los herejes". En este decreto el concilio estableció que la idolatría era un pecado grave, que transitaba al delito. Se hacía la invitación a los prelados a que cuando descubrieran a los indios idólatras se actuara con benevolencia, excepto con los dogmatistas: "procedan contra ellos con medios rigurosos, aplicando las penas que vieren que convienen para enmienda de estos y reparo de los demás". ${ }^{77}$ Jacinto de la Serna cita todo el título para hacer hincapié en que la primera recomendación que hay que tomar en cuenta al detectar a un idólatra es exhortarlo a enmendar su camino, y sólo en los casos más graves, es decir, en los indios poseedores de conocimientos antiguos, debía procederse contra ellos como criminales. Cabe destacar que Serna citó la versión en latín de los decretos. ${ }^{78}$

El título antes referido ponía el acento en los indios dogmatistas, ya que eran éstos los guardianes del antiguo conocimiento de los pueblos indígenas y los culpables de llevarlo a la población en general. Por ello eran considerados como individuos peligrosos, porque incitaban a los demás a practicar actos idolátricos. Como ya mencionamos arriba, Jacinto de la Serna ubicaba a los médicos indígenas como dogmatistas, pues eran ellos los guardianes del conocimiento sobre la salud y la enfermedad.

En ese último apartado se enlazan la parte teológica y la parte jurídica. En la primera se anuncia que la idolatría sería una forma de romper el pacto entre los indios y la Iglesia, mientras que en la tercera se refiere a las consecuencias de esa ruptura. La idolatría podía ser por ignorancia o con pleno conocimiento de lo que esto significaba, pero en ambos casos había un desconocimiento de la autoridad y por lo tanto un acto de rebeldía ante la Iglesia y las instituciones novohispanas. Los indios incitadores serían acreedores a sanciones por su mal comportamiento. Además, castigarlos servía como ejemplo de lo que sucedería a aquellos cuyo comportamiento resultara contrario a la ortodoxia católica.

\section{Conclusión}

Hemos sistematizado la manera en que Jacinto de la Serna entendió la idolatría de los indios. Con ello podemos advertir que teorizó en torno a uno de los conceptos más importantes en la religión católica, el de idolatría.

77 Martínez Ferrer, Decretos del Concilio, t. II, 588.

${ }^{78}$ Serna, "Manual de ministros", 465-466. 
En conclusión, podemos decir que el Manual de ministros de Jacinto de la Serna es un estudio que marcó una forma importante de explicar la idolatría de los indios del centro de México en el siglo xvir, que incluye una revisión de grandes teólogos y filósofos, sobre todo de la antigüedad clásica y de la Edad Media, pero que también incluye un referente empírico que se construyó con lo que el propio autor recogió en su andar como beneficiado de un pueblo de indios, lo que le dio acceso a conocimiento directo sobre el campo, así como el intercambio de información con contemporáneos suyos que también tuvieron a su cargo la catequesis de los indios o la administración del culto.

Encontramos definiciones explícitas de idolatría en el texto de Jacinto de la Serna que la definen como un culto inadecuado, que estaba dirigido a Dios pero que incluía elementos religiosos que tenían un origen prehispánico, aunque con una resignificación en un contexto colonial. Debemos ver en la definición de idolatría una categoría cristiana que reconoce al otro, al tiempo que reconoce su diversidad religiosa, pero la considera peligrosa ante el descontento que puede generar en Dios una forma de rendirle culto que no es la institucional. Esto se conecta con la relación entre idolatría y rebeldía, porque la variedad de cultos podía derivar en la ruptura del pacto entre Dios y cristianos.

En el contexto en el que se escribió el Manual de ministros hay una reconfiguración del pensamiento novohispano y encontramos a otros autores que ven en el pasado indígena la grandeza de la historia novohispana, como sucedía con Carlos de Sigüenza y Góngora, mientras que prolifera una literatura religiosa que tiene como objetivo remarcar la idolatría de los indios y la casi imposibilidad de su erradicación.

El Manual de ministros es un documento que brindaba elementos a los religiosos para poder identificar a los dogmatistas, al mismo tiempo que exponía los elementos para dilucidar los caminos a seguir en los casos de encontrar idolatría, ya fuera para utilizar remedios o bien, en casos más graves, para la impartición de la justicia eclesiástica. Es el Manual de ministros un texto muy completo en la conceptualización de la idolatría, porque incluye tanto la acepción teológica como la dimensión jurídica de la idolatría, al tiempo que también incluye un rico material etnográfico en el que las descripciones de las religiosidades indígenas son ampliamente descritas. 


\section{FUENTES}

\section{Documentales}

Archivo del Cabildo de la Catedral Metropolitana de México, Edictos.

Archivo General de Indias, Sevilla, España, Cartas de Audiencia, México; Indiferente; México.

Archivo General de la Nación, México, Indiferente Virreinal e Inquisición.

\section{Bibliografía}

Acosta, Joseph de. De procuranda Indorum salute. Madrid: Consejo Superior de Investigaciones Científicas, 1987.

Alva, Bartolomé de. Confessionario mayor y menor en lengua mexicana. Y platicas contra las supersticiones de idolatria, que el dia de oy an quedado a los Naturales desta Nueva España, e instricion de los Santos Sacramentos. México: Francisco Salbago, impresor del Secreto del Santo Officio, 1664.

Bernand, Carmen, y Serge Gruzinski. De idolatría. Una arqueología de las ciencias religiosas. México: Fondo de Cultura Económica, 1992.

Calles, Roger. “Epílogo.” En Imágenes del bien y del mal, de Martin Buber, 231-256. Buenos Aires: Lilmod, 2006.

Carreño, Alberto María. Efemérides de la Real y Pontificia Universidad de México según sus libros de claustros. México: Universidad Nacional Autónoma de México, Instituto de Investigaciones Históricas, 1963

Castillo Flores, José Gabino. El cabildo eclesiástico de México (1530-1612). Zamora: El Colegio de Michoacán, 2018.

Chimalpáhin, Domingo. Diario. México: Consejo Nacional para la Cultura y las Artes, 2001.

Cook, Noble David. Born to Die. Disease and New World Conquest, 1492-1650. Nueva York: Cambridge University Press, 1999.

Delumeau, Jean. El miedo en Occidente (siglos XIV-XVIII). Una ciudad sitiada. Barcelona: Taurus, 2019.

Díaz Balsera, Viviana. Guardians of Idolatry. Gods, Demons, and Priests in Hernando Ruiz de Alarcon's Treatise on the Heathen Superstitions. Norman: University of Oklahoma Press, 2018.

Duviols, Pierre. La destrucción de las religiones andinas. Conquista y colonia. México: Universidad Nacional Autónoma de México, 1977. 
Estenssoro Funch, Juan Carlos. Del paganismo a la santidad. La incorporación de los indios del Perú al catolicismo, 1532-1750. Lima: Institut Français d'Études Andines, Open Editions Books, 2015.

Foucault, Michel. Obrar mal, decir la verdad. Función de la confesión en la justicia. Curso de Lovaina, 1981. Buenos Aires: Siglo XXI, 2014.

García Cabrera, Juan Carlos. “¿Idólatras congénitos o indios sin doctrina? Dos comprensiones divergentes sobre la idolatría andina en el siglo XVII.” En Los indios ante los foros de justicia religiosa en la Hispanoamérica virreinal. Coord. de Jorge E. Traslosheros y Ana de Zaballa Beascoechea, 95-110. México: Universidad Nacional Autónoma de México, Instituto de Investigaciones Históricas, 2010.

García Soormally, Mina. Idolatry and Construction of the Spanish Empire. Boulder: University Press of Colorado, 2018.

Griffiths, Nicholas. La cruz y la serpiente. La represión y el resurgimiento religioso en el Perú colonial. Lima: Pontificia Universidad Católica del Perú, 1998.

Halbertal, Moshe, y Avishai Margalit. Idolatría. Guerra por imágenes: las raíces de un conflicto milenario. Barcelona: Gedisa, 2003.

Lara Cisneros, Gerardo. ¿Ignorancia invencible? Superstición e idolatría ante el Provisorato de Indios y Chinos del Arzobispado de México en el siglo XVIII. México: Universidad Nacional Autónoma de México, Instituto de Investigaciones Históricas, 2016.

López Austin, Alfredo. "Cuarenta clases de magos en el mundo náhuatl." Estudios de Cultura Náhuatl, n. 7 (1967): 87-117.

Maimónides. Guía de perplejos. Versión León Dujovne, prólogo de Angelina Muñiz-Huberman. México: Consejo Nacional para la Cultura y las Artes, 2001.

Martínez Ferrer, Luis. Decretos del Concilio Tercero Provincial Mexicano (1585). Edición histórico-crítica. Zamora: El Colegio de Michoacán; Roma: Universidad Pontificia de la Santa Cruz, 2009.

Motolinía. "Carta al rey de España.” En Joaquín García Icazbalceta, Colección de documentos para la historia de México. T. I, 251-277. México: Librería de J. M. Andrade, 1858.

Miranda Ojeda, Pedro. "Las sanciones de la fe. Los autos de fe y la aplicación de penas del régimen inquisitorial en el México colonial”. Contribuciones desde Coatepec, n. 14 (enero junio 2008): 61-83.

Puente Luna, José Carlos de la. Los curacas hechiceros de Jauja. Batallas mágicas y legales en el Perú colonial. Lima: Fondo Editorial Pontificia Universidad Católica del Perú, 2007

Real Academia Española. Diccionario de autoridades. En línea, http://web.frl.es/ DA.html. 
Sahagún, Bernandino de. Historia general de las cosas de la Nueva España. México: Consejo Nacional para la Cultura y las Artes, 2000.

Segura Urra, Félix. "Raíces historiográficas y actualidad de la historia de la justicia y el crimen en la Baja Edad Media." Anuario de Historia del Derecho Español, n. 7 (2003): 577-678.

Serna, Jacinto de la. "Manual de ministros de indios para el conocimiento de sus idolatrías, y extirpación de ellas." Anales del Museo Nacional, t. vi (México, 1892): 264-480.

Tavárez, David. Las guerras invisibles. Devociones indígenas, disciplina y disidencia en el México colonial. Oaxaca: Universidad Autónoma Benito Juárez de Oaxaca; Zamora: El Colegio de Michoacán; México: Centro de Investigaciones y Estudios Superiores en Antropología Social; México: Universidad Autónoma Metropolitana Iztapalapa, 2012.

Thiers, Jean-Baptiste. Traité des superstitions qui regardent les sacramens selon l'Ecriture sainte, les décrets des conciles, et les sentimens des saints Peres. París: Jean de Nully, 1704.

Torre Villar, Ernesto de la. Las congregaciones de los pueblos de indios. Fase terminal: aprobaciones y rectificaciones. México: Universidad Nacional Autónoma de México, 1995.

Traslosheros, Jorge. Iglesia, justicia y sociedad en la Nueva España. La Audiencia del Arzobispado de México 1528-1668. México: Porrúa; México: Universidad Iberoamericana, 2004.

Valdés Borja, Ana Silvia. "Jacinto de la Serna." En Historiografía mexicana. Volumen II. La creación de una imagen propia. La tradición española. Tomo 2: Historiografía eclesiástica. Coord. de Rosa Camelo y Patricia Escandón, 1433-1455. México: Universidad Nacional Autónoma de México, Instituto de Investigaciones Históricas, 2012.

Valdés Borja, Ana Silvia. “Jacinto de la Serna: aspectos de su vida y obra.” Tesis de licenciatura en Historia, Universidad Nacional Autónoma de México, 2006.

Villavicencio, Diego Jaymes Ricardo. Luz y méthodo de confesar idolatras y destierro de idolatría. Puebla de los Ángeles: Imprenta de Diego Fernández de León, 1692.

\section{SOBRE LOS AUTORES}

Víctor Manuel Ávila Ávila

El doctor Ávila Ávila se encuentra adscrito a la Escuela Nacional de Estudios Superiores-Unidad Morelia de la Universidad Nacional Autónoma de México. 
Sus líneas de investigación son religiosidades indígenas e idolatría novohispana. Entre sus publicaciones recientes destaca "La idolatría entre las Leyes Nuevas y el Primer Concilio Provincial Mexicano. Un proyecto catequético de Juan de Zumárraga”, en Gerardo Lara Cisneros y Roberto Martínez, coords., El ídolo y las hogueras. Idolatría y evangelización en América virreinal, siglos XVI-XVIII, en prensa.

Cecilia López Ridaura

La doctora López Ridaura se encuentra adscrita a la Escuela Nacional de Estudios Superiores-Unidad Morelia, Universidad Nacional Autónoma de México. Sus líneas de investigación se centran en las literaturas populares y la brujería novohispana. Entre sus publicaciones recientes destacan: "Los fetiches de María Guadalupe, un caso de la Inquisición novohispana en Michoacán en el siglo XvıIı”, en María Jesús Zamora Calvo, ed., Mujeres quebradas. La Inquisición y su violencia hacia la heterodoxia en Nueva España (Madrid: Iberoamericana-Vervuert, 2018), 277304; y “'Que sosiego no encuentre': impresos damnificatorios”, Boletín de Literatura Oral, volumen extraordinario, n. 2 (2019): 165-193, https:// doi.org/10.17561/blo.vextrai2.12. 